\title{
Long-term treatment with responsive brain stimulation in adults with refractory partial seizures
}

OPEN

Gregory K. Bergey, MD Martha J. Morrell, MD Eli M. Mizrahi, MD Alica Goldman, MD, PhD David King-Stephens, MD Dileep Nair, MD

Shraddha Srinivasan, MD Barbara Jobst, MD

Robert E. Gross, MD, PhD Donald C. Shields, MD Gregory Barkley, MD Vicenta Salanova, MD Piotr Olejniczak, MD, PhD Andrew Cole, MD Sydney S. Cash, MD, PhD Katherine Noe, MD, PhD Robert Wharen, MD Gregory Worrell, MD, $\mathrm{PhD}$

Anthony M. Murro, MD Jonathan Edwards, MD Michael Duchowny, MD David Spencer, MD Michael Smith, MD Eric Geller, MD Ryder Gwinn, MD Christopher Skidmore, MD Stephan Eisenschenk, MD Michel Berg, MD Christianne Heck, MD

Paul Van Ness, MD

Nathan Fountain, MD

Paul Rutecki, MD

Andrew Massey, MD

Cormac O'Donovan, MD

Douglas Labar, MD, PhD

Robert B. Duckrow, MD

Lawrence J. Hirsch, MD

Tracy Courtney, BS, CCRP

Felice T. Sun, PhD Cairn G. Seale, MS

Correspondence to Dr. Morrell: mmorrell@neuropace.com

\section{ABSTRACT}

Objective: The long-term efficacy and safety of responsive direct neurostimulation was assessed in adults with medically refractory partial onset seizures.

Methods: All participants were treated with a cranially implanted responsive neurostimulator that delivers stimulation to 1 or 2 seizure foci via chronically implanted electrodes when specific electrocorticographic patterns are detected (RNS System). Participants had completed a 2-year primarily open-label safety study $(n=65)$ or a 2-year randomized blinded controlled safety and efficacy study ( $n=191$ ); 230 participants transitioned into an ongoing 7-year study to assess safety and efficacy.

Results: The average participant was 34 ( \pm 11.4 ) years old with epilepsy for $19.6( \pm 11.4)$ years. The median preimplant frequency of disabling partial or generalized tonic-clonic seizures was 10.2 seizures a month. The median percent seizure reduction in the randomized blinded controlled trial was $44 \%$ at 1 year and $53 \%$ at 2 years $(p<0.0001$, generalized estimating equation) and ranged from $48 \%$ to $66 \%$ over postimplant years 3 through 6 in the long-term study. Improvements in quality of life were maintained ( $p<0.05)$. The most common serious devicerelated adverse events over the mean 5.4 years of follow-up were implant site infection $(9.0 \%)$ involving soft tissue and neurostimulator explantation (4.7\%).

Conclusions: The RNS System is the first direct brain responsive neurostimulator. Acute and sustained efficacy and safety were demonstrated in adults with medically refractory partial onset seizures arising from 1 or 2 foci over a mean follow-up of 5.4 years. This experience supports the RNS System as a treatment option for refractory partial seizures.

Classification of evidence: This study provides Class IV evidence that for adults with medically refractory partial onset seizures, responsive direct cortical stimulation reduces seizures and improves quality of life over a mean follow-up of 5.4 years. Neurology ${ }^{\circledR} 2015 ; 84: 810-817$

\section{GLOSSARY}

$\mathbf{A E}=$ adverse event; $\mathbf{C l}=$ confidence interval; $\mathbf{D B S}=$ deep brain stimulation; $\mathbf{E C o G}=$ electrocorticographic; $\mathbf{L T T}=$ LongTerm Treatment; QOLIE-89 = Quality Of Life In Epilepsy Inventory-89; SAE = serious adverse event; SUDEP = sudden unexplained death in epilepsy; VNS = vagus nerve stimulation.

Stimulation therapies have demonstrated efficacy and safety as adjunctive treatments for medically intractable partial onset seizures. The vagus nerve stimulator (VNS Therapy System, Cyberonics, Houston, TX) provides scheduled (open-loop) stimulation to a peripheral nerve and reduced partial seizure frequency by $24.5 \%-28 \%$ during the blinded period of randomized controlled trials $s^{1,2}$ and demonstrated median seizure reductions in a prospective open-label study of $35 \%$ at 1 year and $43 \%$ at 3 years. ${ }^{3,4}$ A randomized controlled trial of scheduled deep brain stimulation (DBS) of the anterior nucleus of the thalamus showed reductions in partial seizures of $41 \%$ at 13 months and $56 \%$ at 26 months. ${ }^{5}$

The RNS System is the first responsive (closed-loop) focal cortical stimulator for use as an adjunctive therapy indicated for adults (18 years or older, refractory to 2 or more antiepileptic drugs) having

Author affiliations are provided at the end of the article.

Go to Neurology.org for full disclosures. Funding information and disclosures deemed relevant by the authors, if any, are provided at the end of the article. The Article Processing Charge was paid by NeuroPace.

This is an open access article distributed under the terms of the Creative Commons Attribution-Noncommercial No Derivative 3.0 License, which permits downloading and sharing the work provided it is properly cited. The work cannot be changed in any way or used commercially. 
frequent and disabling partial onset seizures localized to no more than 2 epileptogenic foci by diagnostic testing. The RNS System was approved by the US Food and Drug Administration $^{6}$ in this patient population for reducing seizure frequency based on a multicenter double-blinded randomized sham-stimulation controlled trial and an earlier feasibility study. ${ }^{7,8}$

This report is from an ongoing 7-year multicenter prospective open-label study for participants who completed the feasibility or pivotal studies in order to provide data on longerterm safety and efficacy.

METHODS The RNS System (NeuroPace, Mountain View, $\mathrm{CA})$ provides responsive (closed-loop) stimulation directly to 1 or 2 seizure foci when abnormal electrocorticographic (ECoG) activity is detected, typically epileptiform activity that has been observed at the onset of electrographic seizures. A cranially implanted programmable neurostimulator is connected to depth or subdural cortical strip leads that are surgically placed at 1 or 2 previously identified seizure foci. Each lead contains 4 electrode contacts (figure 1). As many as 4 leads could be implanted in the clinical trials (no more than 2 depth leads), although only 2 leads can be connected to the neurostimulator at a time. The neurostimulator continually senses ECoG activity through the electrodes and is programmed by the physician to detect specific ECoG patterns and deliver brief stimulus pulses in response to detections. The physician adjusts detection and stimulation parameters for each patient as needed for seizure reduction.?

The Long-Term Treatment (LTT) Study is an ongoing long-term efficacy and safety of the RNS System. Participants had completed the feasibility or pivotal studies (figure 2). Adverse event (AE) and daily seizure diary data were collected every 6 months at a minimum. Quality of life was assessed yearly by the Quality Of Life In Epilepsy Inventory-89 (QOLIE-89). ${ }^{10}$

Efficacy was assessed as median percent change in seizures and as responder rate (the percentage of participants with a $50 \%$ or greater reduction in seizures) for each 3 -month period compared to the preimplant baseline. Average changes in the QOLIE-89 overall $\mathrm{T}$ score and primary scale $\mathrm{T}$ scores were compared to the preimplant baseline using a paired $t$ test.

An independent data monitoring committee reviewed all AEs and a second committee determined whether deaths met criteria for sudden unexplained death in epilepsy (SUDEP).

Editorial, page 768

Supplemental data at Neurology.org by the institutional review boards of participating investigation sites. All participants gave written informed consent. The studies were registered on www.clinicaltrials.gov (NCT00572195). 7-year multicenter prospective open-label study to evaluate the Antiepileptic medications were adjusted as medically necessary.

cutoff date, resulting in an accumulated experience of 1,389 patient implant years and 1,293 patient stimulation years. The mean and median follow-up period was 5.4 patient implant years (SD 2.1 years, range 5 weeks -9.6 years). Participant accountability is provided in figure 2 .

Participant demographics and clinical characteristics are provided in table 1. Most participants had experienced frequent seizures for many years. Onethird had been treated with vagus nerve stimulation (VNS) or epilepsy surgery, and almost two-thirds had been evaluated for epilepsy surgery with intracranial electrodes.

Efficacy. Seizure reduction. The reduction in seizures in participants treated with responsive neurostimulation increased progressively over the first 2 years of treatment and remained stable over years of follow-up (table 2).

Results of the randomized, sham stimulation controlled pivotal trial, which were previously reported, ${ }^{7,8}$ are summarized here. During the randomized blinded period of the pivotal study (months 3 through 5 after implant), the overall seizure reduction in the participants receiving active responsive stimulation (37.9\%) was greater than in the participants receiving sham stimulation (17.3\%) relative to baseline $(p=0.012$, generalized estimating equation). ${ }^{7}$ In the first month of the blinded period, seizure reduction in the treatment group was $34.2 \%$, increasing to $38.1 \%$ in the second month and reaching $41.5 \%$ in the final month. Reductions in seizures were similar in those with mesial temporal and neocortical onsets, in those with 1 and 2 seizure onset foci, in patients with and without prior intracranial monitoring, and in those treated and not treated with VNS or with epilepsy surgery. ${ }^{1}$

During the open-label period of the pivotal study, the median percent reduction in seizures was $44 \%$ at 1 year and $53 \%$ at 2 years postimplant, a significant improvement over time $(p<0.0001) .{ }^{8}$ The reduction in seizures was similar in participants who had changes in their antiseizure medications $(\mathrm{n}=98)$ and those who did not $(n=88){ }^{8}$

The reduction in seizures continued over years of Standard protocol approvals, registrations, and patient follow-up in the LTT Study (table 2). The median consents (IDE G030126). All study protocols were approved percent reduction in seizures was 60\% at the begin-

All analyses include data up to November 1, 2013, with the exception of data on deaths and SUDEP, which were as of July 15,2014

RESULTS A total of 256 participants were implanted with the neurostimulator and leads and 230 of these participants enrolled in the LTT Study. A total of 191 participants continued to participate as of this data ning of year 3 , and $66 \%$ at the beginning of year 6 . The responder rates at the same time points were $58 \%$ and $59 \%$, respectively. To assess possible enrichment of the population due to participant withdrawals, an adjusted responder rate was calculated, which included all participants who had withdrawn due to lack of efficacy or to pursue other treatments. The adjusted responder rates for those same time points (years 3 and 6) were $58 \%$ and $56 \%$, respectively (table e-1 on the Neurology ${ }^{\circledR}$ Web site at Neurology.org). 
Figure 1 Implanted RNS neurostimulator and NeuroPace cortical strip and depth leads

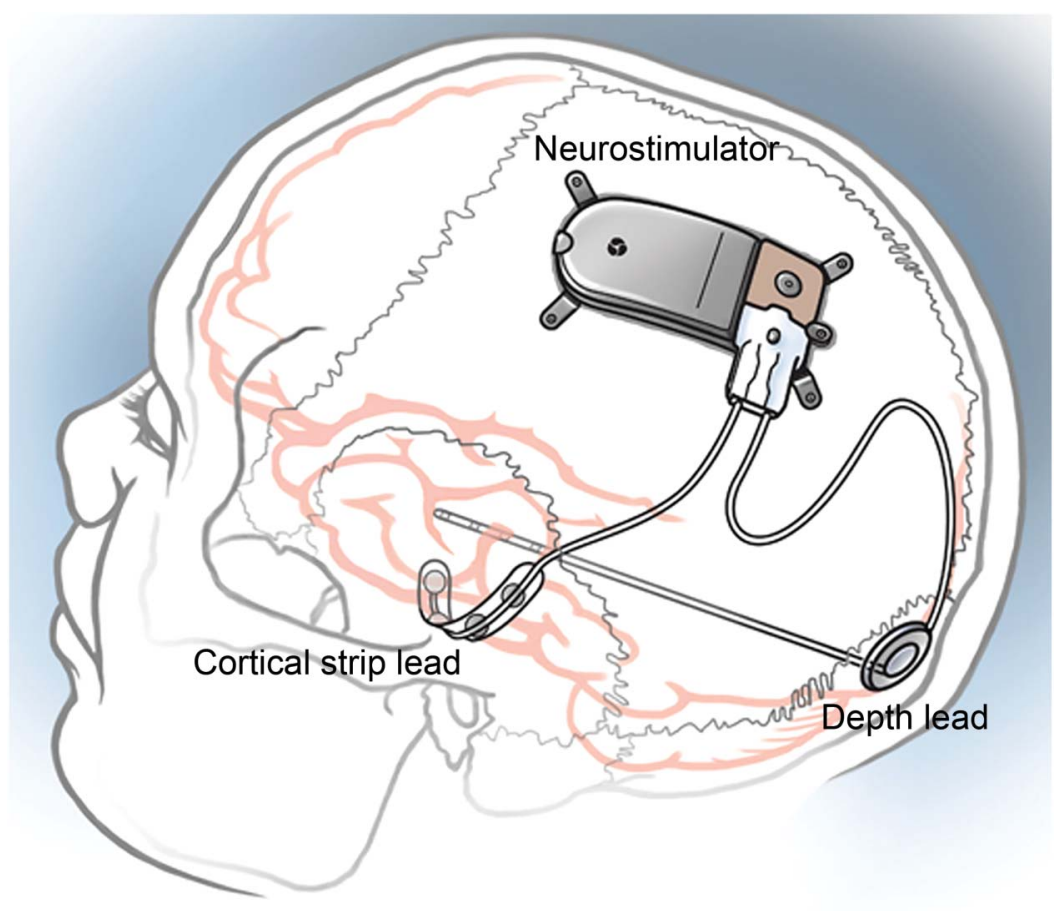

Copyright owned by NeuroPace, Inc; no permissions for use are required.

Seizure frequency decreased in the majority of participants treated with responsive stimulation. Based on the most recent 3 months of available data for each participant (a last observation carried forward analysis for those with 3 complete months of data), $84 \%$ of participants (207/247) had some improvement, 60\% (146/ 247 ) had a $50 \%$ or greater reduction (compared to $8 \%$

Figure 2 RNS System studies: Participant accountability

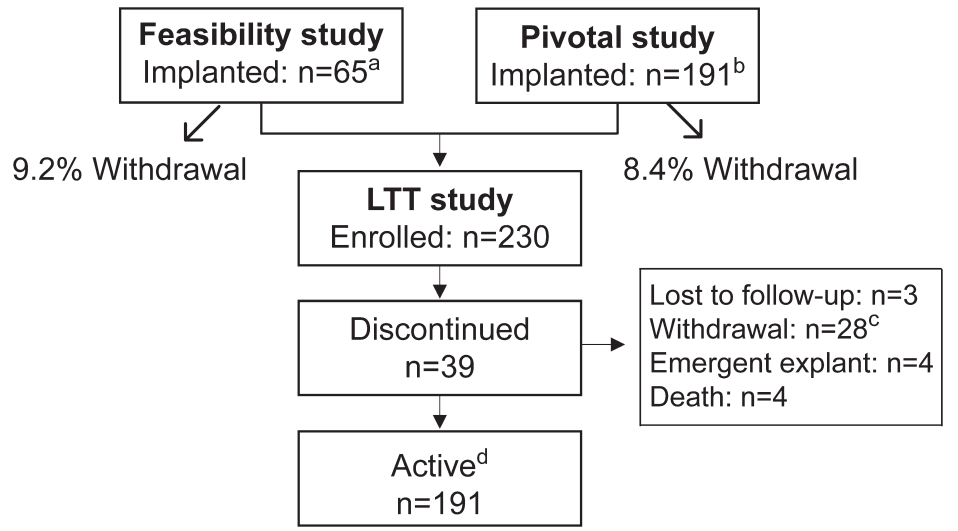

a Six participants discontinued before completing the study; 2 participants completed the study, but elected not to enroll in the Long-Term Treatment (LTT) Study. ${ }^{b}$ Fourteen participants discontinued prior to completing the study; 4 participants completed the study, but elected not to enroll in the LTT Study. ${ }^{c}$ Discontinuation reasons: to pursue other treatments (9); insufficient efficacy (5); participant chose not to replace neurostimulator after expected battery depletion (5) or after resolution of infection (4); noncompliance (3); elective explant (1); ongoing suicidality/noncompliance (1). d Study ongoing; data as of November 1, 2013.
[19/247] with a $50 \%$ or greater increase), and $16 \%$ of participants (40/247) were seizure-free.

Some participants had extended periods of seizure freedom. Over one-third (36.7\%) of the $256 \mathrm{im}$ planted participants had at least 1 seizure-free period of 3 months or longer, $23.0 \%$ had at least 1 seizurefree period of 6 months or longer, and $12.9 \%$ had at least 1 seizure-free period of 1 year or longer. No participants were seizure-free over the entire follow-up.

Antiseizure medications were frequently adjusted during the open-label follow-up. Sixty-three percent of the responders and $70 \%$ of the nonresponders had a new antiseizure medication added, and $9 \%$ of the responders and $8 \%$ of the nonresponders had a reduction in the number or dosage of antiseizure medications.

Quality of life. Quality of life improved at 1 year postimplant $(\mathrm{n}=214$, average $=+3.26, \mathrm{SD}=$ 8.54, $p<0.001)$ and improvements were maintained through year $5(\mathrm{n}=147$, average $=+2.15, \mathrm{SD}=$ 10.75, $p<0.01$ ). To assess for possible enrichment of the population due to participant withdrawals, the change from baseline was calculated by using a last observation carried forward analysis for those participants who withdrew due to lack of efficacy or to pursue other treatments. The improvement from baseline remained statistically significant through year $4(p<$ $0.001)$ and there was a trend toward significance at year $5(p=0.061)$. After 5 years, the sample sizes were not sufficient to reliably assess statistical significance. Improvements were also seen on the QOLIE-89 primary scales of attention, health discouragement, language, memory, overall quality of life, seizure worry, and work and social function $(p<0.05)$. There were no trends toward declines in any primary scale score (QOLIE data available in table e-2).

Safety. Over all studies, serious AEs (SAEs) were primarily anticipated events related to an implanted device or to seizures, and because of hospitalizations for video EEG monitoring. SAEs that occurred in $2.5 \%$ or more of the participants at any time after implant are provided in table 3 .

SAEs of particular concern with any implanted medical device or in persons with epilepsy were considered in detail. SAEs related to any type of intracranial hemorrhage occurred in $4.7 \%$ of participants (12) and the majority of these were in the first days after the initial implant (2 participants with an epidural hematoma, 1 with a subdural hematoma, and 1 with a CT-diagnosed asymptomatic intraventricular hemorrhage), or were associated with seizure-related head trauma (3 participants with subdural hematomas, 1 with a subarachnoid hemorrhage, and 1 with a traumatic intracranial hemorrhage). There were no neurologic sequelae. There were 3 postoperative intracranial hemorrhages that were not related to 
Table 1 Participant demographics and characteristics (all implanted participants $n=256$ )

\begin{tabular}{|c|c|}
\hline Characteristics & Values \\
\hline Female, \% (n) & $49(125 / 256)$ \\
\hline Age, $y_{1}{ }^{a}$ mean $\pm S D$ (range) & $34.0 \pm 11.4(18-66)$ \\
\hline Duration of epilepsy, $y_{1}{ }^{a}$ mean $\pm S D$ (range) & $19.6 \pm 11.4(2-57)$ \\
\hline $\begin{array}{l}\text { Current number of antiseizure medications, }{ }^{a} \\
\text { mean } \pm \text { SD (range) }\end{array}$ & $2.9 \pm 1.1(0-8)$ \\
\hline $\begin{array}{l}\text { Preimplant frequency of simple partial motor, } \\
\text { complex partial, and secondarily generalized tonic-clonic } \\
\text { seizures per month, mean, } \pm \text { SD (range); median }\end{array}$ & $50.7 \pm 177.4(0-2,320)^{\mathrm{b}} ; 10.2$ \\
\hline Prior intracranial monitoring, \% (n) & $65(166 / 256)$ \\
\hline Prior epilepsy surgery, \% (n) & $34(86 / 256)$ \\
\hline Prior vagus nerve stimulation, \% (n) & $32(82 / 256)$ \\
\hline Two seizure foci (vs 1), \% (n) & $48(124 / 256)$ \\
\hline Mesial temporal lobe onset, \% (n) & $43(111 / 256)$ \\
\hline Bilateral & $72(80)$ \\
\hline Left & $19(21)$ \\
\hline Right & $9(10)$ \\
\hline Neocortical onset, \% (n) & $49.2(126 / 256)$ \\
\hline Frontal & $38(48)$ \\
\hline Temporal & $45(57)$ \\
\hline Parietal & $14(17)$ \\
\hline Occipital & $3(4)$ \\
\hline Mesial as well as neocortical onset, \% (n) & $7.4(19 / 256)$ \\
\hline
\end{tabular}

seizures. One participant with 3 cortical strip leads had a cerebral hemorrhage in year 3 postimplant and had mild right hand paresis; this participant had the neurostimulator and leads explanted 18 months later. The second participant had 2 depth and 2 cortical strip leads and had a subtemporal hematoma 2.5 years after implant that led to an exacerbation of a preexisting memory deficit. The third participant had 4 cortical strip leads and experienced a cerebral hemorrhage 2.8 years after implant that caused a persistent headache. Both the second and third participants continued to be treated with responsive stimulation.

All implant site infections or erosions leading to an SAE were superficial soft tissue infections. Five participants $(2.0 \%)$ had a postoperative implant site infection; one of these 5 participants had the neurostimulator and leads explanted. After the postoperative period, 20 participants (including one of the 5 participants who had a postoperative infection) had an SAE related to a soft tissue implant site infection; 2 of these were attributed to seizure-related head trauma, and the remainder followed a neurostimulator replacement. All participants were treated with antibiotics; 2 participants had their neurostimulator replaced, 14 had the neurostimulator explanted (10 participants also had the leads explanted), and 2 participants were later reimplanted. There were no infections of the brain or subdural space, no sepsis, and no long-lasting neurologic or medical consequences.

Other SAEs reported in $2.5 \%$ or more of the participants were related to changes in seizures that were considered serious because the participant was admitted to the hospital for observation or for IV antiseizure medication. None of these events occurred with initiation of stimulation and no participant withdrew from any of the studies because of a seizure-related SAE.

There were 11 deaths: 2 by suicide in patients with a history of depression (1 that occurred when responsive stimulation was off), 1 due to status epilepticus in a participant who had subtherapeutic levels of antiseizure medications, and 1 due to lymphoma. Seven of the 11 deaths were attributed to possible, probable, or definite SUDEP; 2 occurred while responsive stimulation was off. The rate of probable or definite SUDEP for participants implanted with the RNS System was 3.5 per 1,000 patient implant years (confidence interval [CI] 1.5-8.5) and 2.6 per 1,000 patient stimulation years (CI 1.0-7.0).

DISCUSSION Responsive (closed-loop) neurostimulation is a new approach to treating epilepsy. Stimulation is delivered to the seizure focus in response to epileptiform activity. Similar to adjusting the dose of an antiseizure medication to maximize efficacy and tolerability, detection and stimulation parameters can be adjusted to improve clinical benefits and avoid stimulation-related adverse events.

In the most general sense, epilepsy is a disorder in the balance of excitation and inhibition. In partial epilepsy, the disturbance may be well-localized, but electrical activity spreads monosynaptically and polysynaptically to other regions to create the symptoms of the clinical seizure. The objective of responsive neurostimulation is to identify the critical region or propagation pathways and to then provide neutralizing, disruptive, or driving activity in order to restore normal function. ${ }^{11}$

Treatment with the RNS System provided a significant and sustained reduction in seizures and improved quality of life in adults with many years of partial onset seizures that were resistant to multiple antiseizure medications and in many cases to VNS or epilepsy surgery.

A double-blinded randomized controlled study of the RNS System as an adjunctive treatment for adults with medically intractable partial seizures arising from 1 or 2 seizure foci ${ }^{1,8}$ demonstrated a progressive reduction in seizures from implant through the second year after implant. These interim results of a prospective open-label long-term study indicate that 


\begin{tabular}{|c|c|c|c|}
\hline \multirow[t]{2}{*}{ Table 2} & \multicolumn{3}{|c|}{$\begin{array}{l}\text { Long-term seizure reduction: Long-Term Treatment Study ( } n=230 \\
\text { enrolled, ongoing) }\end{array}$} \\
\hline & $\mathrm{No}^{\mathrm{a}}$ & $\begin{array}{l}\text { Median \% reduction } \\
\text { (1st quartile, 3rd quartile) }\end{array}$ & $\begin{array}{l}\text { Responder rate }(95 \% \\
\text { confidence interval) }\end{array}$ \\
\hline \multicolumn{4}{|l|}{ Year 3} \\
\hline Months $36-38$ & 214 & $60.0(24.2,85.8)$ & $57.9(51.3-64.4)$ \\
\hline Months 39-41 & 216 & $57.2(21.4,86.0)$ & $56.0(49.4-62.5)$ \\
\hline Months 42-44 & 212 & $62.1(27.8,89.7)$ & 59.9 (53.2-66.3) \\
\hline Months 45-47 & 208 & $65.9(33.2,88.5)$ & $60.6(53.8-67.0)$ \\
\hline \multicolumn{4}{|l|}{ Year 4} \\
\hline Months 48-50 & 204 & $63.3(29.8,91.2)$ & $60.8(53.9-67.2)$ \\
\hline Months 51-53 & 202 & $62.2(25.1,89.6)$ & $62.4(55.5-68.8)$ \\
\hline Months 54-56 & 196 & $64.8(21.5,88.1)$ & $60.7(53.7-67.3)$ \\
\hline Months 57-59 & 197 & $61.8(23.8,88.9)$ & $61.4(54.5-67.9)$ \\
\hline \multicolumn{4}{|l|}{ Year 5} \\
\hline Months 60-62 & 172 & $65.5(23.2,91.2)$ & $61.0(53.6-68.0)$ \\
\hline Months 63-65 & 161 & $60.7(21.4,91.6)$ & $60.9(53.2-68.1)$ \\
\hline Months 66-68 & 142 & $62.4(25.0,92.2)$ & $59.9(51.6-67.6)$ \\
\hline Months 69-71 & 117 & $48.1(14.8,86.2)$ & $49.6(40.7-58.5)$ \\
\hline \multicolumn{4}{|l|}{ Year 6} \\
\hline Months 72-74 & 115 & $65.7(30.6,87.1)$ & $59.1(50.0-67.7)$ \\
\hline
\end{tabular}

${ }^{a}$ No. represents participants who have reached that time point in the ongoing study.

${ }^{\mathrm{b}}$ The $95 \%$ confidence interval was calculated using the Wald method.

the median percent seizure reduction is sustained at $60 \%$ or greater over additional years of follow-up. The majority of participants benefitted from treatment with the RNS System, and 23\% experienced at least one 6-month period of seizure freedom.

Increased efficacy over the first 1-2 years of stimulation therapy is reported with other devices for treatment of partial onset seizures such as VNS ${ }^{4,12}$ and DBS of the anterior nucleus of the thalamus. ${ }^{6}$ In addition, progressive improvement in the therapeutic response has been observed with stimulation of the anterior cingulate cortex for depression, ${ }^{11}$ subthalamic nucleus, anterior limb of the internal capsule, and nucleus accumbus for obsessive-compulsive disorder, ${ }^{13}$ and globus pallidus for primary dystonia. ${ }^{14}$

The observations of an acute and delayed therapeutic effect of brain stimulation suggest multiple mechanisms of action. ${ }^{11}$ Acute effects of stimulation could be related to changes in cellular inhibition or excitation, to changes in cerebral blood flow, or to axonal and glial release of neurotransmitters. ${ }^{15-18}$ Changes in synaptic plasticity, neurogenesis, or cortical reorganization may be responsible for the effects over time. ${ }^{11,19,20}$ Responsive neurostimulation can adapt to these dynamic physiologic changes, which might offer an advantage over nonresponsive, scheduled, or continuous stimulation.

Responsive neurostimulation was well-tolerated and safe over time and adverse events related to the
Table $3 \quad$ Serious adverse events affecting $\geq 2.5 \%$ of implanted participants (1,389 patient implant years with mean follow-up of 5.4 years)

\begin{tabular}{ll} 
& $\begin{array}{l}\text { Participants with } \\
\text { serious adverse } \\
\text { events, \% (n) }\end{array}$ \\
\hline Implant site infection & $9.4(24)$ \\
Complex partial seizures increased & $7.8(20)$ \\
\hline EEG monitoringa & $7.2(44)$ \\
\hline Therapeutic agent toxicity & $7.0(18)$ \\
\hline $\begin{array}{l}\text { Tonic-clonic seizures increased } \\
\text { (more frequent) }\end{array}$ & $5.9(15)$ \\
\hline Medical device removal & \\
\hline $\begin{array}{l}\text { Tonic-clonic seizures exacerbated } \\
\text { (more severe) }\end{array}$ & $5.5(14)$ \\
\hline Death & $4.7(12)$ \\
\hline Premature battery depletion & \\
\hline Device lead damage & $4.3(11)$ \\
\hline Depression suicidal & $4.3(11)$ \\
\hline Device lead revision & $3.5(9)$ \\
\hline Nonconvulsive status epilepticus & $3.1(8)$ \\
\hline Pneumonia & $3.1(8)$ \\
\hline Convulsive status epilepticus & $2.7(7)$ \\
\hline Skin laceration (due to seizure) & $2.7(7)$ \\
\hline Suicide attempt & $2.7(7)$ \\
\hline
\end{tabular}

Study ongoing; data as of November 1, 2013.

${ }^{a}$ Considered a serious adverse event due to admission to an epilepsy monitoring unit.

${ }^{\mathrm{b}}$ Led to hospital admission in all 18 participants; 16 due to antiseizure medication toxicity.

' Pursue other treatments (8), insufficient efficacy (4), participant elected (2).

${ }^{d}$ Occurred with battery from manufacturer that is no longer in use.

implanted device, including hemorrhage and infection, were anticipated and the rates were not higher than reported with implantation of intracranial electrodes to localize the seizure focus ${ }^{21-23}$ and with epilepsy surgery, ${ }^{21,24,25}$ or with DBS devices for treatment of movement disorders. ${ }^{26}$ The number of seizure-related adverse events was not higher than in randomized controlled trials of medications for adjunctive treatment of partial onset seizures. ${ }^{27-30}$ Deaths, including deaths by SUDEP, were not more frequent than is expected in patients with medically intractable partial onset seizures. ${ }^{31,32}$

The Institute of Medicine ${ }^{33}$ concluded that at least $30 \%$ of adults with partial onset seizures ${ }^{27,28}$ do not achieve seizure control with antiepileptic medications and a similar percentage have significant medicationrelated side effects. ${ }^{27,28,34,35}$ Some of these patients will consider epilepsy surgery or a vagus nerve stimulator. However, not all patients are candidates for these treatments and these treatments do not always provide 
meaningful benefit. New treatments are needed that can provide better seizure control and are well-tolerated.

The clinical meaningfulness of the response to treatment with the RNS System is supported by significant improvements in overall quality of life and in individual domains that indicate a more positive perception of cognitive function, relationships and social function, overall health, and vulnerability to seizures. These are areas of function that are often profoundly impacted in persons with intractable seizures. ${ }^{33,36-38}$

Retention rate is an important metric of patient satisfaction and is a clinically meaningful composite of efficacy and safety. ${ }^{39}$ In the RNS System studies, the majority of participants chose to continue treatment, indicating that treatment was perceived to be of benefit. The 1-year discontinuation rate was 3.9\%, whereas 1-year discontinuation rates in trials of approved antiseizure medications range from $23 \%$ to $77 \% .^{40,41}$ Ninety-seven percent of patients chose to continue treatment by enrolling into the LTT Study. Discontinuation of treatment simply required that the neurostimulator be programmed off since all components of the device may be left in place. These rates compare favorably to retention rates in trials of other approved epilepsy therapies, including VNS and antiseizure medications. The majority of discontinuations in antiseizure medication trials are due to medicationrelated side effects such as cognitive and behavioral side effects, and other AEs such as nausea, sedation, dizziness, and rash (55\%-77\%). ${ }^{39}$ These types of adverse events were not common with treatment with the RNS System.

There are limitations to any open-label study. Potential confounds include a regression from a higher than usual baseline seizure frequency to a more typical frequency during the treatment period. The participant and physician may have a positive bias towards therapeutic efficacy. However, these are unlikely to explain the seizure reduction over years in patients who have failed many treatment trials.

The RNS System is the first device that provides responsive neurostimulation and has shown acute and sustained efficacy, tolerability, and safety in adults with medically intractable partial onset seizures. Future research and clinical experience will provide additional understanding about patient selection, stimulation targets, and stimulation parameters. Fundamental research into the mechanisms of action of brain stimulation will facilitate its clinical application. The accumulated experience demonstrates that responsive neurostimulation provides another treatment option for patients with medically intractable partial onset seizures who are not good candidates for epilepsy surgery.

\section{AUTHOR AFFILIATIONS}

From Johns Hopkins Medicine (G.K.B.), Baltimore, MD; Stanford University (M.J.M.), CA; Baylor College of Medicine (E.M.M., A.G.),
Houston, TX; California Pacific Medical Center (D.K.-S.), San Francisco; Cleveland Clinic Foundation (D.N.), OH; Columbia University Medical Center (S.S.), New York, NY; Dartmouth-Hitchcock Medical Center (B.J.), Lebanon, NH; Emory University (R.E.G.), Atlanta, GA; George Washington University (D.C.S.), Washington, DC; Henry Ford Hospital (G.B.), Detroit, MI; Indiana University School of Medicine (V.S.), Indianapolis; Louisiana State University Health Science Center (P.O.), New Orleans; Massachusetts General Hospital (A.C., S.S.C.), Boston; Mayo Clinic Arizona (K.N.), Scottsdale; Mayo Clinic Florida (R.W.), Jacksonville; Mayo Clinic Rochester (G.W.), MN; Georgia Regents University (A.M.M.), Augusta; Medical University of South Carolina (J.E.), Charleston; Miami Children's Hospital (M.D.), FL; Oregon Health \& Science University (D.S.), Portland; Rush University Medical Center (M.S.), Chicago, IL; Institute of Neurology and Neurosurgery at St. Barnabas (E.G.), Livingston, NJ; Swedish Neuroscience Institute (R.G.), Seattle, WA; Thomas Jefferson University (C.S.), Philadelphia, PA; University of Florida (S.E.), Gainesville; University of Rochester (M.B.), NY; University of Southern California (C.H.), Los Angeles; University of Texas Southwestern Medical Center (P.V.N.), Dallas; University of Virginia School of Medicine (N.F.), Charlottesville; University of Wisconsin (P.R.), Madison; Via Christi Comprehensive Epilepsy Center (A.M.), Wichita, KS; Wake Forest University (C.O.), Winston-Salem, NC; Weill Medical College of Cornell University (D.L.), New York, NY; Yale University School of Medicine (R.B.D., L.J.H.), New Haven, CT; and NeuroPace (M.J.M., T.C., F.T.S., C.G.S.), Mountain View, CA.

\section{AUTHOR CONTRIBUTIONS}

Gregory K. Bergey cowrote the manuscript with Dr. Martha Morrell and was involved in data collection and interpretation. The following authors contributed to the manuscript as follows: data collection, data interpretation, and manuscript writing or review: Eli M. Mizrahi, Alica Goldman, David King-Stephens, Dileep R. Nair, Shraddha Srinivasan, Barbara C. Jobst, Robert E. Gross, Donald C. Shields, Gregory L. Barkley, Vicenta Salanova, Piotr Olejniczak, Andrew J. Cole, Sydney S. Cash, Katherine Noe, Robert E. Wharen, Gregory A. Worrell, Anthony M. Murro, Jonathan C. Edwards, Michael Duchowny, David C. Spencer, Michael C. Smith, Eric Geller, Ryder P. Gwinn, Christopher Skidmore, Stephan Eisenschenk, Michel J. Berg, Christianne N. Heck, Paul C. Van Ness, Nathan B. Fountain, MD, Paul A. Rutecki, Andrew D. Massey, Cormac A. O’Donovan, Douglas Labar, Robert B. Duckrow, Lawrence J. Hirsch, Tracy Courtney, Felice T. Sun, Cairn G. Seale.

\section{ACKNOWLEDGMENT}

The following individuals served as investigators and clinical coordinators and contributed to the research conducted (protocol procedures, data collection, and data reporting). Baylor College of Medicine: Ronnie Tobias, Daniel Yoshor, MD. California Pacific Medical Center: Kenneth Laxer, MD, Douglas Raggett, Peter Weber, MD. Cleveland Clinic Foundation: Andreas Alexopoulos, MD, William Bingaman, MD, Deborah Johnston, Lara Jehi, MD, Prakash Kotagal, MD. Weill Medical College of Cornell University: Padmaja Kandula, MD, Olga Akselrod, Mattson Ogg, Bill Nikolov, Theodore Schwartz, MD. Columbia University Medical Center: Carl Bazil, MD, Guy McKhann, MD, Jacqueline Wooley. DartmouthHitchcock Medical Center: Faith Alexandre, Krzysztof Bujarski, MD, Karen Secore, Erik Kobylarz, MD, David Roberts, MD, Vijay Thadani, MD. Emory University: Charles Epstein, MD, Sandra Helmers, MD, Emilee Wehunt, Suzette LaRoche, MD. George Washington University: Andria Bailey, Samuel Potolicchio, MD, Stacy Tam. Henry Ford Hospital: Helen Foley, Shailaja Gaddam, MD, Jason Schwalb, MD, Marianna Spanaki-Varelas, MD, Vibhangini Wasade, MD. Indiana University School of Medicine: Nicholas Barbaro, MD, Caitlin Camp, Linda Perdue, Meridith Runke, MD, Dragos Sabau, MD, Thomas Witt, MD, Robert Worth, MD. Johns Hopkins Medicine: William Anderson, MD, Joanne Barnett, Pamela Coe, George Jallo, MD, Eric Kossoff, MD, Frederick Lenz, MD, Eva Ritzl, MD. Louisiana State University Health Sciences Center: Edward Mader, MD, Nicole Villemarette-Pittman. Mayo Clinic Arizona: Erica Boyd, Joseph Drazkowski, MD, Naresh Patel, MD, Joseph Sirven, MD. Mayo Clinic Florida: Karey Doll, Daniel Large, Jerry Shih, MD, William Tatum, MD. Mayo Clinic Rochester: Jeffrey Britton, MD, Gregory Cascino, MD, Karla Crockett, W. Richard Marsh, MD, 
Cindy Nelson. Georgia Regents University: Cole Giller, MD, Yong Park, MD, Patty Ray. Massachusetts General Hospital: Samantha Donovan, Emad Eskandar, MD, Daniel Hoch, MD, Tara Jennings. Miami Children's Hospital: Sanjiv Bhatia, MD, Ian Miller, MD, Stephanie Perez, Tami Quintero, John Ragheb, MD. Medical University of South Carolina: Jonathan Halford, MD, Kimberly Schnabel, Alexander Vandergrift, MD. Oregon Health \& Science University: James Cereghino, MD, Martin Salinski, MD, Chad Sorenson. Rush University Medical Center: Richard Byrne, MD, Thomas Hoeppner, MD, Sarah Perpich, Marvin Rossi, MD, Josephine Volgi, Deborah Zielinski. Institute of Neurology and Neurosurgery at St. Barnabas: Werner Doyle, MD, Jade Misajon. Swedish Neuroscience Institute: Lisa Caylor, MD, Michael Doherty, MD, Caryl Tongco. Thomas Jefferson University: James Evans, MD, Victoria Fairchild, Aaron Fedor, Scott Mintzer, MD, Maromi Nei, MD, Ashwin Sharan, MD, Michael Sperling, MD. University of Florida, Gainesville: Jean Cibula, MD, Steven Roper, MD, Kyle Rizer. University of Rochester: Noreen Connolly, A. James Fessler, MD, Lynn Liu, MD, Webster Pilcher MD, Olga Selioutski, MD, Diane Smith, Thomas Wychowski, MD. University of Southern California: Guadalupe Corral-Leyva, Laura Kalayjian, MD, Brian Lee, MD, Charles Liu, MD, Sandra Oviedo. University of Texas Southwestern Medical Center: Mark Agostini, MD, Puneet Gupta, MD, Erica Howard, Christopher Madden, MD, Pradeep Modur, MD, Lauren Smith, Dinah Turner-Knight, Louis Whitworth, MD. University of Virginia School of Medicine: William Elias, MD, Bruce Palmer, Stacy Thompson. University of Wisconsin: Azam Ahmed, MD, Andrea Maser Christopher Roginski, Evelyn Tunnell, MD. Via Christi Comprehensive Epilepsy Center: Aamr Herekar, MD, Nazih Moufarrij, MD, Toni Sadler. Wake Forest University Health Sciences: Daniel Couture, MD, Maria Sam, MD, Sara Vaughan. Yale University School of Medicine: Jennifer Bonito, Jason Gerrard, MD, Dennis Spencer, MD.

\section{STUDY FUNDING}

NeuroPace provided funding for the clinical study and is responsible for the study design. All investigator authors were responsible for data collection. The sponsor, the lead author, and the other investigator authors contributed to data interpretation and preparation/review of the manuscript.

\section{DISCLOSURE}

M. Morrell is a NeuroPace employee (equity ownership). G. Bergey is a NeuroPace Advisory Board Member, not paid. E. Mizrahi, A. Goldman, D. King-Stephens, D. Nair, and S. Srinivasan report no disclosures relevant to the manuscript. B. Jobst is a NeuroPace Advisory Board Member, paid. R. Gross serves as a consultant to NeuroPace and receives compensation for these services. NeuroPace develops products related to the research described in this article. The terms of this arrangement have been reviewed and approved by Emory University in accordance with its conflict of interest policies. D. Shields, G. Barkley, V. Salanova, and P. Olejniczak report no disclosures relevant to the manuscript. A. Cole is a NeuroPace Advisory Board Member, paid. S. Cash, K. Noe, and R. Wharen report no disclosures relevant to the manuscript. G. Worrell is a NeuroPace Advisory Board Member, not paid. A. Murro, J. Edwards, M. Duchowny, D. Spencer, M. Smith, and E. Geller report no disclosures relevant to the manuscript. R. Gwinn is a NeuroPace Advisory Board Member, paid. C. Skidmore, S. Eisenschenk, and M. Berg report no disclosures relevant to the manuscript. C. Heck is a NeuroPace Advisory Board Member, paid. P. Van Ness is a NeuroPace Advisory Board Member, not paid. N. Fountain, P. Rutecki, A. Massey, C. O’Donovan, D. Labar, and R. Duckrow report no disclosures relevant to the manuscript. L. Hirsch is a NeuroPace Advisory Board Member, paid. T. Courtney is a NeuroPace employee (equity ownership). F. Sun is a NeuroPace employee (equity ownership). C. Seale is a NeuroPace employee (equity ownership). Go to Neurology.org for full disclosures.

Received March 31, 2014. Accepted in final form November 3, 2014.

\section{REFERENCES}

1. Morrell MJ; RNS System in Epilepsy Study Group. Responsive cortical stimulation for the treatment of medically intractable partial epilepsy. Neurology 2011; 77:1295-1304.

2. The Vagus Nerve Stimulation Study Group. A randomized controlled trial of chronic vagus nerve stimulation for treatment of medically intractable seizures. Neurology 1995;45:224-230.

3. Handforth A, DeGiorgio CM, Schachter SC, et al. Vagus nerve stimulation therapy for partial-onset seizures: a randomized active-control trial. Neurology 1998;51:48-55.

4. Morris GL III, Mueller WM. Long-term treatment with vagus nerve stimulation in patients with refractory epilepsy: The Vagus Nerve Stimulation Study Group E01E05. Neurology 1999;53:1731-1735.

5. Morris GL III, Gloss D, Buchhalter J, Mack KJ, Nickels K, Harden C. Evidence-based guideline update: vagus nerve stimulation for the treatment of epilepsy: report of the Guideline Development Subcommittee of the American Academy of Neurology. Neurology 2013;81:1453-1459.

6. Fisher R, Salanova V, Witt T, et al. Electrical stimulation of the anterior nucleus of thalamus for treatment of refractory epilepsy. Epilepsia 2010;51:899-908.

7. RNS System, Summary of Safety and Effectiveness, P100026. U S Department of Health and Human Services, Food and Drug Administration. Available at: www. accessdata.fda.gov/cdrh_docs/pdf10/p100026b.pdf. Accessed August 14, 2014.

8. Heck CN, King-Stephens D, Massey AD, et al. Two-year seizure reduction in adults with medically intractable partial onset epilepsy treated with responsive neurostimulation: final results of the RNS System Pivotal trial. Epilepsia 2014;55:432-441.

9. Sun FT, Morrell MJ. Closed-loop neurostimulation: the clinical experience. Neurotherapeutics 2014;11:553-563.

10. Devinsky O, Vickrey BG, Cramer J, et al. Development of the quality of life in epilepsy inventory. Epilepsia 1995;36: 1089-1104.

11. Lozano AM, Lipsman N. Probing and regulating dysfunctional circuits using deep brain stimulation. Neuron 2013; 77:406-424.

12. DeGiorgio CM, Schachter SC, Handforth A, et al. Prospective long-term study of vagus nerve stimulation for the treatment of refractory seizures. Epilepsia 2000;41:1195-1200.

13. Greenberg BD, Malone DA, Friehs GM, et al. Three-year outcomes in deep brain stimulation for highly resistant obsessive-compulsive disorder. Neuropsychopharmacology 2006;31:2384-2393.

14. Isaias IU, Alterman RL, Tagliati M. Deep brain stimulation for primary generalized dystonia: long-term outcomes. Arch Neurol 2009;66:465-470.

15. Hess CW, Vaillancourt DE, Okun MS. The temporal pattern of stimulation may be important to the mechanism of deep brain stimulation. Exp Neurol 2013;247:296-302.

16. Feng Z, Zheng X, Yu Y, Durand DM. Functional disconnection of axonal fibers generated by high frequency stimulation in the hippocampal CA1 region in-vivo. Brain Res 2013;1509:32-42.

17. Jensen AL, Durand DM. High frequency stimulation can block axonal conduction. Exp Neurol 2009;220:57-70.

18. Hashimoto T, Elder CM, Okun MS, Patrick SK, Vitek JL. Stimulation of the subthalamic nucleus changes the firing pattern of pallidal neurons. J Neurosci 2003;23: 1916-1923. 
19. Stone SS, Teixeira CM, Devito LM, et al. Stimulation of entorhinal cortex promotes adult neurogenesis and facilitates spatial memory. J Neurosci 2011;31:13469-13484.

20. Stavrinou LC, Boviatsis EJ, Stathis P, Leonardos A, Panourias IG, Sakas DE. Sustained relief after discontinuation of DBS for dystonia: implications for the possible role of synaptic plasticity and cortical reorganization. J Neurol Surg A Cent Eur Neurosurg 2012;73:175-178.

21. Behrens E, Schramm J, Zentner J, Konig R. Surgical and neurological complications in a series of 708 epilepsy surgery procedures. Neurosurgery 1997;41:1-9.

22. Wong $\mathrm{CH}$, Birkett J, Byth $\mathrm{K}$, et al. Risk factors for complications during intracranial electrode recording in presurgical evaluation of drug resistant partial epilepsy. Acta Neurochir 2009;151:37-50.

23. Silberbusch MA, Rothman MI, Bergey GK, Zoarski GH, Zagardo MT. Subdural grid implantation for intracranial EEG recording: CT and MR appearance. AJNR Am J Neuroradiol 1998;19:1089-1093.

24. Engel J Jr, Wiebe S, French J, et al. Practice parameter: temporal lobe and localized neocortical resections for epilepsy: report of the Quality Standards Subcommittee of the American Academy of Neurology, in association with the American Epilepsy Society and the American Association of Neurological Surgeons. Neurology 2003; 60:538-547.

25. Wiebe S, Blume WT, Girvin JP, Eliasziw M. A randomized, controlled trial of surgery for temporal-lobe epilepsy. N Engl J Med 2001;345:311-318.

26. Weaver FM, Follett K, Stern M, et al. Bilateral deep brain stimulation vs best medical therapy for patients with advanced Parkinson disease: a randomized controlled trial. JAMA 2009;301:63-73.

27. Marson AG, Al-Kharusi A, Alwaidh M, et al. The SANAD study of effectiveness of carbamazepine, gabapentin, lamotrigine, oxcarbazepine, or topiramate for treatment of partial epilepsy: an unblinded randomised controlled trial Lancet 2007;369:1000-1015.

28. French JA, Kanner AM, Bautista J, et al. Efficacy and tolerability of the new antiepileptic drugs II: treatment of refractory epilepsy: report of the Therapeutics and Technology Assessment Subcommittee and Quality Standards Subcommittee of the American Academy of Neurology and the American Epilepsy Society. Neurology 2004; 62:1261-1273.
29. Krauss GL, Perucca E, Ben-Menachem E, et al. Perampanel, a selective, noncompetitive alpha-amino-3-hydroxy-5methyl-4-isoxazolepropionic acid receptor antagonist, as adjunctive therapy for refractory partial-onset seizures: interim results from phase III, extension study 307. Epilepsia 2013;54:126-134.

30. Ben-Menachem E, Biton V, Jatuzis D, bou-Khalil B, Doty P, Rudd GD. Efficacy and safety of oral lacosamide as adjunctive therapy in adults with partial-onset seizures. Epilepsia 2007;48:1308-1317.

31. Shorvon S, Tomson T. Sudden unexpected death in epilepsy. Lancet 2011;378:2028-2038.

32. Dasheiff RM. Sudden unexpected death in epilepsy: a series from an epilepsy surgery program and speculation on the relationship to sudden cardiac death. J Clin Neurophysiol 1991;8:216-222.

33. Institute of Medicine. Epilepsy Across the Spectrum: Promoting Health and Understanding. Washington, DC: The National Academies Press; 2012.

34. Perucca P, Carter J, Vahle V, Gilliam FG. Adverse antiepileptic drug effects: toward a clinically and neurobiologically relevant taxonomy. Neurology 2009;72:1223-1229.

35. Zaccara G, Franciotta D, Perucca E. Idiosyncratic adverse reactions to antiepileptic drugs. Epilepsia 2007; 48:1223-1244.

36. Hermann BP, Seidenberg M, Dow C, et al. Cognitive prognosis in chronic temporal lobe epilepsy. Ann Neurol 2006;60:80-87.

37. Leidy NK, Elixhauser A, Vickrey B, Means E, Willian MK. Seizure frequency and the health-related quality of life of adults with epilepsy. Neurology 1999; 53:162-166.

38. Loring DW, Meador KJ, Lee GP. Determinants of quality of life in epilepsy. Epilepsy Behav 2004;5:976-980.

39. Bootsma HP, Ricker L, Hekster YA, et al. The impact of side effects on long-term retention in three new antiepileptic drugs. Seizure 2009;18:327-331.

40. Zaccara G, Messori A, Cincotta M, Burchini G. Comparison of the efficacy and tolerability of new antiepileptic drugs: what can we learn from long-term studies? Acta Neurol Scand 2006;114:157-168.

41. Chung S, Wang N, Hank N. Comparative retention rates and long-term tolerability of new antiepileptic drugs. Seizure 2007;16:296-304.

\section{Save These Dates for AAN CME Opportunities!}

Mark these dates on your calendar for exciting continuing education conferences by the American Academy of Neurology. Learn more at AAN.com/conferences.

\section{AAN Annual Meeting}

- April 18-25, 2015, Washington, DC, Walter E. Washington Convention Center 


\section{Neurology}

\section{Long-term treatment with responsive brain stimulation in adults with refractory partial seizures}

Gregory K. Bergey, Martha J. Morrell, Eli M. Mizrahi, et al.

Neurology 2015;84;810-817 Published Online before print January 23, 2015

DOI 10.1212/WNL.0000000000001280

This information is current as of January 23, 2015

\section{Updated Information \&} Services

Supplementary Material

\section{References}

Citations

Subspecialty Collections

Permissions \& Licensing

Reprints including high resolution figures, can be found at:

http://n.neurology.org/content/84/8/810.full

Supplementary material can be found at:

http://n.neurology.org/content/suppl/2015/01/23/WNL.0000000000001 280.DC1

http://n.neurology.org/content/suppl/2015/01/23/WNL.0000000000001 280.DC2

This article cites 39 articles, 11 of which you can access for free at: http://n.neurology.org/content/84/8/810.full\#ref-list-1

This article has been cited by 9 HighWire-hosted articles: http://n.neurology.org/content/84/8/810.full\#\#otherarticles

This article, along with others on similar topics, appears in the following collection(s):

\section{Partial seizures}

http://n.neurology.org/cgi/collection/partial_seizures

Information about reproducing this article in parts (figures,tables) or in its entirety can be found online at:

http://www.neurology.org/about/about_the_journal\#permissions

Information about ordering reprints can be found online:

http://n.neurology.org/subscribers/advertise

Neurology ${ }^{\circledR}$ is the official journal of the American Academy of Neurology. Published continuously since 1951, it is now a weekly with 48 issues per year. Copyright (C 2015 American Academy of Neurology. All rights reserved. Print ISSN: 0028-3878. Online ISSN: 1526-632X.

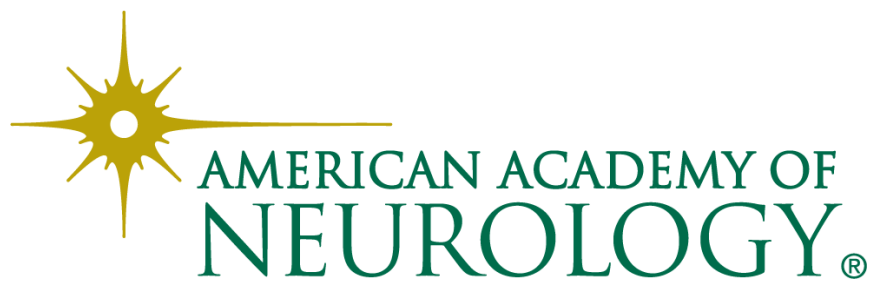

